(6)

OPEN ACCESS

\title{
Shrinking of a Tarlov cyst
}

\author{
Kieran P Murphy, ${ }^{1}$ Susannah Ryan ${ }^{2}$
}

'Medical Imaging, University Health Network, Toronto,

Ontario, Canada

${ }^{2}$ Royal College of Surgeons in Ireland School of Medicine, Dublin, Ireland

\section{Correspondence to} Professor Kieran P Murphy, kieran.murphy@uhn.ca

Accepted 7 February 2019

\begin{abstract}
SUMMARY
A 65-year-old patient presenting with left labial and perirectal pain was diagnosed with bilateral Tarlov cysts. Upon treatment of the left Tarlov cyst (the right was asymptomatic) using image-guided aspiration and subsequent injection of the cyst with fibrin sealant, the cyst reduced in size. To our knowledge, there are currently no other documented cases in which the Tarlov cyst reduced in size following this procedure. This case would seem to suggest that clinicians are poorly informed with regard to Tarlov cysts. These cysts are more common in Caucasian women, many of whom are told their cysts are not responsible for their pain or that they are not treatable. However, there is clear evidence that some Tarlov cysts are symptomatic and minimally invasive procedures have been developed to treat them. As they primarily occur in women, it is possible gender bias may also play a role in the delayed diagnosis of the patient's pain.
\end{abstract}

\section{BACKGROUND}

Tarlov cysts were first described in 1938 by Tarlov as an incidental finding during autopsy. ${ }^{1}$ Tarlov

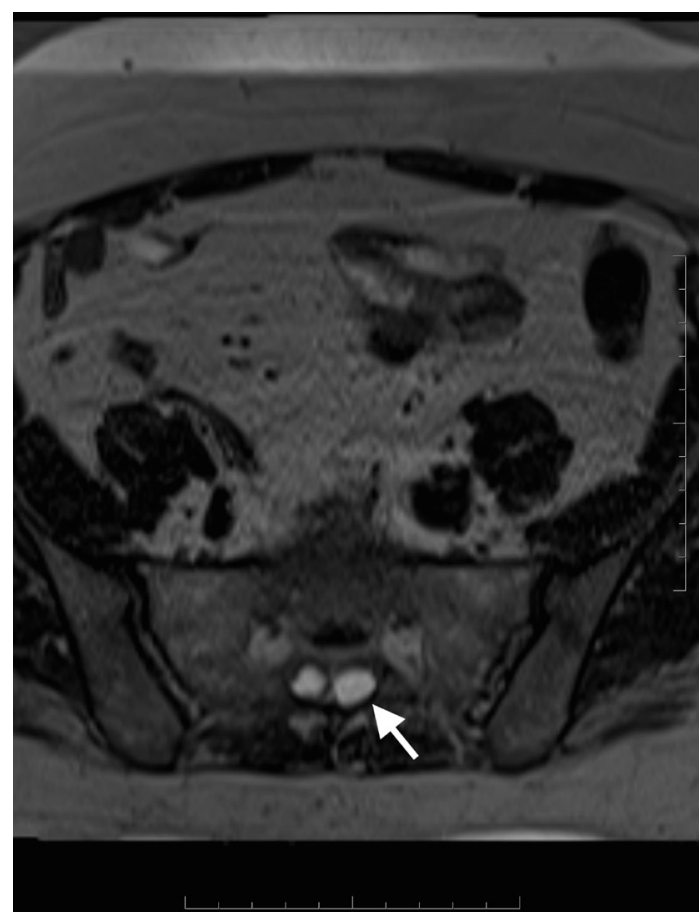

Figure 1 Axial T2 weighted MRI in 2012 demonstrated the presence of bilateral Tarlov cysts at the level of S2. The left cyst was slightly larger than the right (see arrow pointing to left cyst) and measured $1.9 \times 1 \times 1.3 \mathrm{~cm}$. The left cyst also compressed the left $\$ 1$ nerve root. There was also some mild bony erosion associated with the left cyst. cysts are one of many mimics of discogenic radiculopathy with a reported incidence of $4.6 \%$ in back pain patients, $20 \%$ of which are symptomatic. ${ }^{2} \mathrm{~A}$ 2013 case report published in the New England Journal of Medicine found that in previous large studies, the prevalence of symptomatic Tarlov cysts found on lumbosacral MRI images ranged from $1.5 \%-2.1 \% .^{3}$ A more recent study published in 2017 by Kuhn et al assessed 1100 sacral MRIs, finding sacral Tarlov cysts in 132 cases (13.2\%). They also found that the prevalence of Tarlov cysts appeared to increase with age. ${ }^{4}$ They are most commonly found in Caucasian women. ${ }^{2}$ Also known as perineural cysts, Tarlov cysts are cerebrospinal-fluid-filled meningeal dilations of nerve roots, most often found in the spinal canal of the S1-S5 region of the spinal cord. ${ }^{1}$ They can, however, be found in the cervical, thoracic and lumbar regions. ${ }^{5}$ The aetiology of Tarlov cysts is not well understood, however, several hypotheses have been proposed, which may be either congenital or acquired. Congenital causes include connective tissue disorders such as Loeys Dietz, Ehlers-Danlos and Marfan syndromes ${ }^{6}$ while acquired causes include inflammation within the nerve root cysts, arachnoidal proliferation around and along the exiting nerve root, haemorrhagic infiltration of the spinal tissue and breakage of the venous drainage in the perineurium and epineurium secondary to haemosiderin deposition after trauma. ${ }^{8}$ Tarlov cysts can cause backache, sciatica, perineal, buttock and lower extremity pain as well as sexual, urinary and bowel dysfunction but are often ignored on MRI or thought to be of little significance in causing back pain. ${ }^{9-11}$ Lumbosacral MRI and CT myelography are the most common methods of diagnosing Tarlov cysts, however, dedicated sacral MRI is more sensitive. ${ }^{11}$ Treatment options include non-surgical lumbar cerebrospinal fluid drainage and percutaneous cyst drainage, as well as surgical options such as cyst fenestration, cyst wall resection, simple decompressive laminectomy and myofascial flap repair and closure. ${ }^{10} 12$ More recently, less-invasive procedures to treat Tarlov cysts have been described, including the two-needle technique, which has been employed in this case. ${ }^{10}$ Prior to this procedure, cysts are injected with lidocaine or Marcaine. This is a functional test to determine if the cysts are symptomatic. ${ }^{10}$ In our experience, in at least $50 \%$ of cases they are not the cause. Herein, we present a case of a Tarlov cyst which reduced in size following image-guided aspiration of the cyst with subsequent injection of fibrin glue into the cyst using the two-needle technique. 


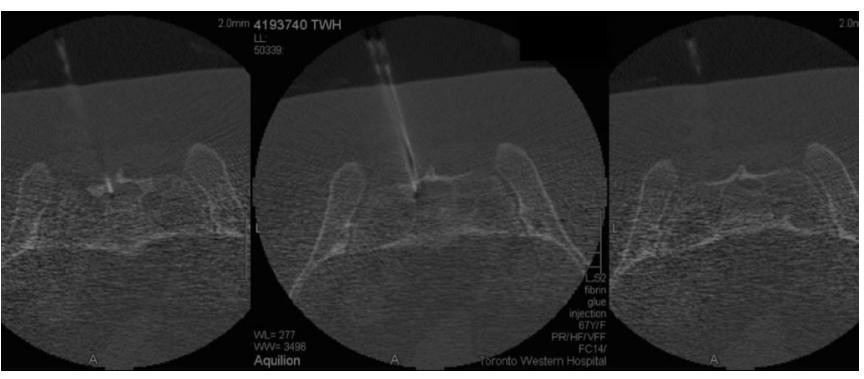

Figure 2 In May 2016, the patient underwent treatment of symptomatic Tarlov cysts using two 18-gauge needles. The tip of the first needle was placed deep into the cyst, with the other being placed more superficially. About $2 \mathrm{~mL}$ of cerebrospinal fluid was aspirated. $0.5 \mathrm{cc}$ of Marcaine and $2 \mathrm{~mL}$ of fibrin glue were injected into the cyst, via the deep needle.

\section{CASE PRESENTATION}

A 65 -year-old woman presented with a 14-year history of left labial and left perirectal pain along the distribution of the S2 dermatome. This pain was described as a low grade, constant, stabbing, burning pain that had become intense 2 years prior. The patient was a highly functional individual, however, the pain had begun to severely affect her daily life. The patient had been using topical lidocaine for pain relief.

\section{INVESTIGATIONS}

In 2012, an MRI was performed (figure 1) and demonstrated the presence of bilateral Tarlov cysts at the level of S2, within the

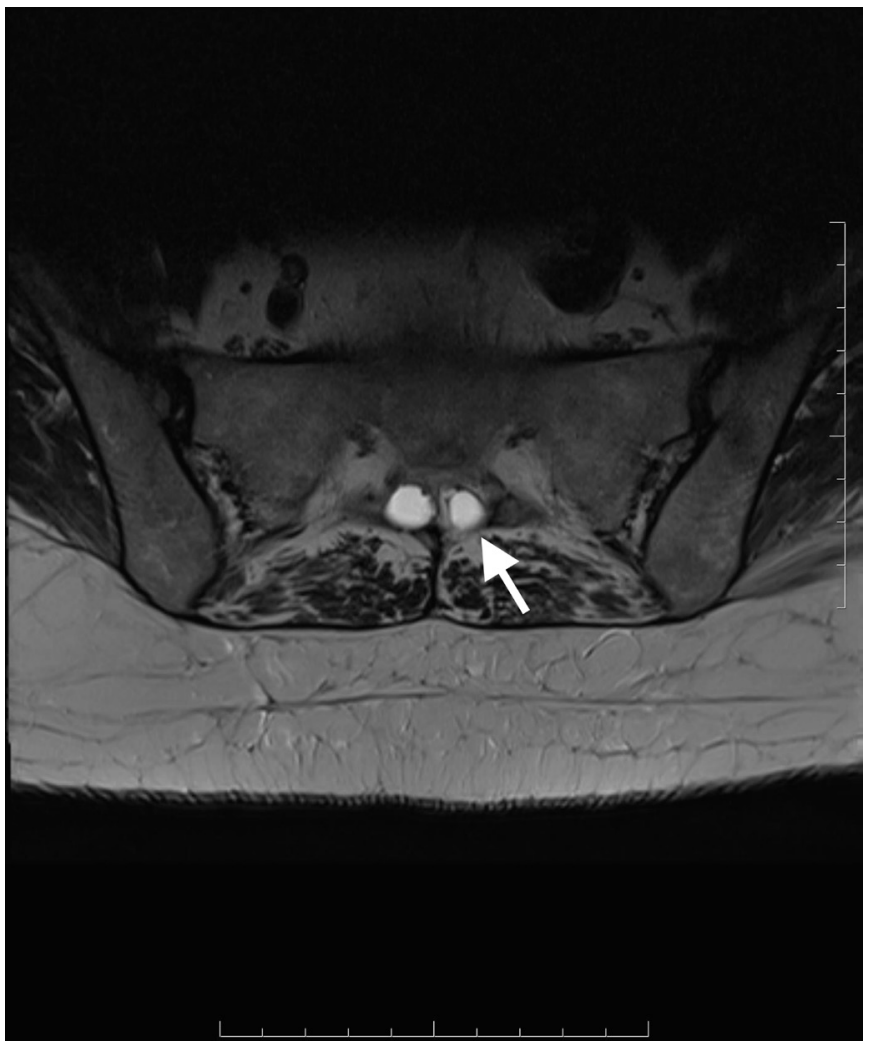

Figure 3 MRI in May 2018 was compared with the prior MRI of 2012. The comparison demonstrates an interval decrease in the size of the left Tarlov cyst (see arrow pointing to left cyst). The left cyst now measures $1.4 \times 0.8 \times 0.9 \mathrm{~cm}$. The left Tarlov cyst is now significantly smaller than the right, though previously it was larger. sacral canal. The left cyst was slightly larger than the right (see arrow pointing to left cyst) and measured $1.9 \times 1 \times 1.3 \mathrm{~cm}$. The left cyst also compressed the left S1 nerve root. There was also some mild bony erosion associated with the left cyst.

\section{DIFFERENTIAL DIAGNOSIS}

The initial differential diagnoses included yeast infection, pudendal neuropathy, cyclical sciatica and piriformis syndrome. The patient had a history of endometriosis but had a hysterectomy thirty years prior. Tarlov cysts were not suspected as the cause of pain until they were recognised on an outpatient MRI.

\section{TREATMENT}

After reviewing the images, it was decided to perform a functional test, which involved cyst aspiration and lidocaine injection under CT fluoroscopic guidance, to determine if the Tarlov cyst was symptomatic and responsible for the patient's pain. Dependent upon the patient's response, a second procedure involving fibrin glue injection was planned. Informed consent was obtained from the patient for the procedure after discussion of the risks, which include numbness, infection and bleeding, and benefits.

In September 2014 under CT fluoroscopic guidance, two 18 -gauge needles were gently passed through the lamina of the left S2 and entered the left Tarlov cyst. A small amount of fluid was aspirated and $0.5 \mathrm{cc} 1 \%$ lidocaine was injected. After lidocaine injection, the patient experienced complete resolution of her pain. The patient was observed for 1 hour as part of standard protocol and then discharged.

The patient had an excellent prolonged response with complete reduction in pain and tenderness. However, at 1-year follow-up, she stated that she had been experiencing a gradual increase in symptoms. Repeat MRI was performed, demonstrating no significant change in the appearance of the cyst. It was determined that the patient would be an ideal candidate for fibrin glue injection as the functional test confirmed that this cyst was responsible for her symptoms. In May 2016, informed consent was obtained from the patient after discussion of the risks and benefits associated with the procedure. The area was prepared with a sterile technique, and numbed by injection of local anaesthesia into the skin, fat, muscle and periosteum overlying the sacrum. The two-needle technique for the treatment of symptomatic Tarlov cysts was performed (figure 2). Two 18 -gauge needles were passed into the left Tarlov cyst. ${ }^{10}$ The tip of the first needle was placed deep into the cyst, with the other being placed more superficially. ${ }^{10}$ About $2 \mathrm{~mL}$ of cerebrospinal fluid (CSF) was aspirated. $0.5 \mathrm{cc}$ of Marcaine and $2 \mathrm{~mL}$ of fibrin glue were injected into the cyst, via the deep needle. There were no complications to the procedure and both needles were removed. The puncture sites were cleaned, treated with an antibiotic ointment and covered with a sterile dressing. The patient was observed for 2 hours as per standard protocol and was reviewed prior to discharge.

\section{OUTCOME AND FOLLOW-UP}

This procedure provided pain relief for 18 months. The patient then presented with recurrent but significantly reduced pain and discomfort. MRI of the spine was performed.

The follow-up MRI in May 2018 (figure 3) was compared with an MRI performed in 2012 prior to aspiration of the cyst and injection with fibrin sealant. The comparison demonstrates an interval decrease in the size of the left Tarlov cyst. The left cyst previously measured $1.9 \times 1 \times 1.3 \mathrm{~cm}$ and now measures $1.4 \times 0.8 \times 0.9 \mathrm{~cm}$. The left Tarlov cyst is now significantly smaller 
than the right (see arrow pointing to left cyst), having previously been larger. The MRI also showed new anterior disc space Modic 1 degenerative disc disease in the L5-S1 region, which is believed to be the cause of the patient's current back pain.

\section{DISCUSSION}

Tarlov cysts were first described in 1938 by neurosurgeon, Isadore Tarlov. They were an incidental finding during autopsy and were initially thought to be asymptomatic. ${ }^{1}$ Current data indicate that at least some Tarlov cysts are symptomatic. ${ }^{23}$

Open surgical options have proven to be effective yet complications do exist, including infection, loss of sacral nerve function, postoperative CSF leak, and bowel and bladder dysfunction. ${ }^{11}$ Image-guided aspiration of symptomatic Tarlov cysts and their injection with fibrin sealant had been documented as a less-invasive alternative treatment to surgery. Prior to this case, it had not been documented that injection with fibrin sealant could reduce the size of symptomatic Tarlov cysts. A 2016 article published in the American Journal of Neuroradiology found that $81.8 \%$ of patients treated with this procedure were satisfied with their results at 1 year follow-up and 74\% were satisfied at 3-6-year follow-up. Data from this study also indicate that this treatment option is associated with low morbidity and adverse effects with only 8 of 213 patients suffering from minor complications, including transiently increased pain and one case of mild non-specific allergic reaction with scattered hives, all of which resolved without incident. ${ }^{11}$ The reduction in size of the Tarlov cysts following injection with fibrin sealant was not mentioned in this 2016 study and to our knowledge, this finding has not yet been documented elsewhere. It is believed that injection of the fibrin sealant thickens the cyst wall, blocking the one-way ball valve-like opening at the neck of the cyst. This could prevent spinal fluid from re-entering the cyst, causing its reduction in size. ${ }^{11}$

Tarlov cysts are most commonly found in Caucasian women. ${ }^{2}$ A study carried out in 2013 found that there was a significantly higher incidence of Tarlov cysts in women than in men, and referred to another paper by Landown et al where $70 \%$ of cases were woman. ${ }^{13} 14$ An additional study published in 2013 called 'Tarlov cysts: clinical evaluation of an Italian cohort of patients' had a sample population of 157 patients with symptomatic Tarlov cysts; $88 \%$ were woman. ${ }^{15}$ Another paper published in 2016 documented the treatment of 213 patients with symptomatic Tarlov cysts by CT-guided injection of fibrin sealant. 89.9\% of this patient cohort were woman. ${ }^{11}$

The physician who cared for this patient has had similar experiences caring for patients with Tarlov cysts, most of whom are women. Many of these women had previously been told that their cysts were not the cause of their back pain and had not been offered any treatment options. We believe that it is reasonable to assume that as the majority of these patients were women, gender bias and/or inadequate knowledge of the condition on behalf of the treating clinician were relevant factors in the delayed or complete lack of treatment received by these patients. Studies have found that differences exist in the assessment and treatment of pain depending on gender, race and age. ${ }^{16}$ For example, a 2013 study found that participating healthcare professionals were more likely to administer opioids for pain relief to male patients than to female patients and also rated pain higher in men than their women counterparts. ${ }^{17}$ A 1994 paper entitled 'Pain and its treatment in outpatients with metastatic cancer' found that the female sex was a factor that contributed to predicting inadequate pain treatment. Of the $42 \%$ of patients whose pain was not adequately managed, women were much more likely to be undertreated than men, with an OR of $1.5 .^{18}$ Another paper published in 1996 found that despite the fact that the number one cause of mortality in women is coronary artery

Patient's perspective

Looking back, I realised that I had first noticed discomfort in the labial area when I was 50 years young. A few years later the pain began to have a significant impact on my lifestyle so I began seeking medical help. I was referred from one specialist to another, to another, to another. Each time I was told they could not see the pain and they could do nothing for me. It wasn't until I visited a dermatologist that I was finally referred to a pain clinic.Looking back, I realised that I had first noticed discomfort in the labial area when I was 50 years young. A few years later the pain began to have a significant impact on my lifestyle so I began seeking medical help. I was referred from one specialist to another, to another, to another. Each time I was told they could not see the pain and they could do nothing for me. It wasn't until I visited a dermatologist that I was finally referred to a pain clinic.

After my initial visit with my doctor, the first relief of pain was psychological; I was finally being taken seriously. The treatment was painless (except for the freezing) and I was able to get up, walk away, and take the streetcar/subway/train/car trip home with no discomfort. What an amazing feeling to be able to move about without pain-it was almost euphoric. This continued for another 6 months when the pain slowly started to return although at a much reduced level. Being of high pain tolerance I put off contacting my doctor for another 18 months when he suggested doing a follow-up treatment to include an injection of fibrin. Once again I experienced instant relief.

As more time passed I felt a slight return of pain but no longer sufficient to significantly impact my life although I was beginning to exhibit lower back pain in the area due to an unrelated cause. A follow-up consultation with my doctor indicated that the cyst had shrunk which was compatible with my symptoms and weighing the risks and benefits, I was comfortable to postpone further treatments.

\section{Learning points}

- The injection of lidocaine or Marcaine into a Tarlov cyst can be a functional test to determine if the lesion is symptomatic, while also providing prolonged pain relief.

- Image-guided aspiration of symptomatic Tarlov cysts and injection of fibrin sealant into the cysts using the two-needle technique has been proven to be an effective, safe and lessinvasive alternative to the open surgical treatment of these cysts.

- Current evidence (from this case) proves that in addition to the other benefits this procedure offers, including low morbidity and adverse effects, it may also reduce the size of symptomatic Tarlov cysts, resulting in reduction in pain symptoms.

- There is a need for increased physician awareness about symptomatic Tarlov cysts and the procedures available to treat them.

- Greater awareness on the topic of gender bias in healthcare is also essential. 
disease, those who present to the emergency department with new-onset chest pain and other symptoms similar to those experienced by men are diagnosed and treated less aggressively. ${ }^{19}$

Contributors Professor KPM proposed the idea for this case report, cared for the patient, performed the procedure outlined in the case report, acquired and interpreted the data described in the paper as well as cowriting and editing the paper. SR analysed and interpreted data outlined in the case report, met with the patient and also cowrote the paper.

Funding The authors have not declared a specific grant for this research from any funding agency in the public, commercial or not-for-profit sectors.

Competing interests None declared.

Patient consent for publication Obtained.

Provenance and peer review Not commissioned; externally peer reviewed.

Open access This is an open access article distributed in accordance with the Creative Commons Attribution Non Commercial (CC BY-NC 4.0) license, which permits others to distribute, remix, adapt, build upon this work non-commercially, and license their derivative works on different terms, provided the original work is properly cited and the use is non-commercial. See: http://creativecommons.org/ licenses/by-nc/4.0/

\section{REFERENCES}

1 Tarlov IM. Perineurial cysts of the spinal nerve roots. Arch Neurol Psychiatry 1938:40:1067-74

2 Paulsen RD, Call GA, Murtagh FR. Prevalence and percutaneous drainage of cysts of the sacral nerve root sheath (Tarlov cysts). AJNR Am J Neuroradiol 1994;15:293-7. Discussion 8-9.

3 Oaklander A, Long D, Larvie M, et al. Case 7-2013 — A 77-Year-Old woman with long-standing unilateral thoracic pain and incontinence. N Engl I Med 2013:368:853-61.
4 Kuhn FP, Hammoud S, Lefèvre-Colau M-M, et al. Prevalence of simple and complex sacral perineural Tarlov cysts in a French cohort of adults and children. Journal of Neuroradiology 2017;44:38-43.

5 Tarlov IM. Spinal perineurial and meningeal cysts. J Neurol Neurosurg Psychiatry 1970;33:833-43.

6 Isono M, Hori S, Konishi Y, et al. Ehlers-Danlos syndrome associated with multiple spinal meningeal cysts--case report. Neurol Med Chir 1999;39:380-3.

7 Doi H, Sakurai S, Ida M, et al. [A case of sacral meningeal cyst with Marfan syndrome]. No Shinkei Geka 1999;27:847-50.

8 Guo D, Shu K, Chen R, et al. Microsurgical treatment of symptomatic sacral perineurial cysts. Neurosurgery 2007;60:1059-66.

9 Murphy KJ, Nussbaum DA, Schnupp S, et al. Tarlov cysts: an overlooked clinical problem. Semin Musculoskelet Radiol 2011;15:163-7.

10 Murphy K, Wyse G, Schnupp S, et al. Two-needle technique for the treatment of symptomatic Tarlov cysts. J Vasc Interv Radiol 2008;19:771-3.

11 Murphy K, Oaklander AL, Elias G, et al. Treatment of 213 Patients with Symptomatic Tarlov Cysts by CT-Guided Percutaneous Injection of Fibrin Sealant. AJNR Am J Neuroradiol 2016;37:373-9.

12 Konar SK, Bir SC, Maiti TK, et al. Isadore Max Tarlov (1905-1977) and the controversial Tarlov cyst: historical perspective. J Neurosurg Spine 2016;24:510-3.

13 Burdan F, Mocarska A, Janczarek M, et al. Incidence of spinal perineurial (Tarlov) cysts among East-European patients. PLoS One 2013;8:e71514.

14 Langdown AJ, Grundy JR, Birch NC. The clinical relevance of Tarlov cysts. J Spinal Disord Tech 2005;18:29-33.

15 Marino D, Carluccio MA, Di Donato I, et al. Tarlov cysts: clinical evaluation of an italian cohort of patients. Neurological Sciences 2013:34:1679-82.

16 Hoffmann DE, Tarzian AJ. The girl who cried pain: a bias against women in the treatment of pain. J Law Med Ethics 2001:29:13-27.

17 Wandner LD, Heft MW, Lok BC, et al. The impact of patients' gender, race, and age on health care professionals' pain management decisions: an online survey using virtual human technology. Int J Nurs Stud 2014;51:726-33.

18 Cleeland CS, Gonin R, Hatfield AK, et al. Pain and its treatment in outpatients with metastatic cancer. N Engl J Med 1994;330:592-6.

19 Lehmann JB, Wehner PS, Lehmann CU, et al. Gender bias in the evaluation of chest pain in the emergency department. Am J Cardiol 1996;77:641-4.

Copyright 2019 BMJ Publishing Group. All rights reserved. For permission to reuse any of this content visit

https://www.bmj.com/company/products-services/rights-and-licensing/permissions/

BMJ Case Report Fellows may re-use this article for personal use and teaching without any further permission.

Become a Fellow of BMJ Case Reports today and you can:

- Submit as many cases as you like

- Enjoy fast sympathetic peer review and rapid publication of accepted articles

- Access all the published articles

Re-use any of the published material for personal use and teaching without further permission

For information on Institutional Fellowships contact consortiasales@bmjgroup.com

Visit casereports.bmj.com for more articles like this and to become a Fellow 